\title{
A systematic review and meta-analysis of the application of platelet rich plasma in sports medicine
}

Masoomeh Gholami ${ }^{1}$, Hamid Ravaghi ${ }^{2}$, Masoud Salehi $^{3}$, Amirhosein Abedi Yekta ${ }^{4}$, Shila Doaee ${ }^{5}$, Ebrahim Jaafaripooyan ${ }^{6}$

${ }^{1}$ MS in Health Technology Assessment, Department of Health Sciences Educational Development, School of Public Health, Tehran University of Medical Science, Tehran, Iran

${ }^{2}$ Ph.D. of Health Policy and Management, Assistant Professor, Department of Health Services Management, School of Management and Medical Informatics, Iran University of Medical Science, Tehran, Iran

${ }^{3} \mathrm{Ph}$.D. of Biostatistics, Assistant Professor, Department of Biostatistics, School of Health Sciences, Iran University of Medical Science, Tehran, Iran

${ }^{4}$ Specialist of Sport Medicine, Assistant Professor, Department of Sport and Exercise Medicine, School of Medicine, Shahid Beheshti University of Medical Sciences, Tehran, Iran

${ }^{5}$ MS, Expert officer in Deputy of Treatment Affairs, Ministry of Health and Medical Education (MOHME), Tehran, Iran

${ }^{6}$ Ph.D. of Health Care Management, Assistant Professor, Department of Management Sciences and Health Economics, School of Public Health, Tehran University of Medical Sciences, Tehran, Iran

Type of article: Meta-analysis

\begin{abstract}
Introduction: In recent years, platelet rich plasma (PRP) has been receiving increasing attention for the treatment of soft tissue injuries. These numerous applications have raised a great deal of questions and debate about the effectiveness of this method. This study aimed to determine the efficacy of PRP in improving sports injuries and subsequently throw some light on these controversies.

Methods: A systematic review of the literature and meta-analysis of results were undertaken. All related databases, such as PubMed, Cochrane Database of Systematic Reviews, DARE, and EMBASE, were searched on the use of PRP on athletes and in sports medicine. The search was conducted from June 2013 to February 2014.

Results: Our search retrieved 905 studies, of which 13 randomized control trials (RCT) met our inclusion criteria for systematic review and meta-analysis. All articles were appraised by Critical Appraisal Skills Program (CASP) checklist for RCT studies. The analysis of the results of pain scores and physical activity/functions did not show any superiority for PRP as opposed to the other options.

Conclusions: The meta-analysis showed no more effectiveness for PRP application in sports-related injuries in terms of physical function improvement and pain relief. Therefore, the extensive use of PRP for such injuries should be limited. Well-designed RCTs are needed to support the findings.

Keywords: Platelet rich plasma, Sport medicine, Systematic review, Meta-analysis
\end{abstract}

\section{Introduction}

Platelets are discoid structures blood cells that have no nuclei and are involved in a variety of critical functions in the body. The main function of platelets is hemostasis (coagulation), as well as inflammation, antimicrobial host defense, angiogenesis, and wound healing (1). In healthy individuals normal platelet counts can range from approximately 150,000 to $350,000 / \mu \mathrm{L}$, whereas platelet rich plasma (PRP) is often defined as at least $1,000,000$ platelets $/ \mu \mathrm{L}$ suspended in plasma (2). The logical thought behind PRP is that platelets are the first materials to arrive at the site of injured tissues and thus have the potential to release growth factors that have a critical role in the

\section{Corresponding author:}

Assistant Professor Dr. Ebrahim Jaafaripooyan, Department of Management Sciences and Health Economics, School of Public Health, Tehran University of Medical Sciences, Tehran, Iran.

Tel.: +98.2142933058, Fax: +98.2188989129, Email: Jaafaripooyan@tums.ac.ir

Received: November 11, 2015, Accepted: February 06, 2016, Published: May 2016

iThenticate screening: January 30, 2016, English editing: April 16, 2016, Quality control: May 05, 2016

(C) 2016 The Authors. This is an open access article under the terms of the Creative Commons Attribution-NonCommercialNoDerivs License, which permits use and distribution in any medium, provided the original work is properly cited, the use is non-commercial and no modifications or adaptations are made. 
healing process (3).Sports-related injuries are the main cause of time lost in athletes and teams, and they have a significant effect on society in terms of health care resources, personal disability, and restricted activity. In 2002 , an estimated $\$ 15.8$ billion in total health care expenditures were used in the medical management of these injuries (4). Tendinopathy and muscle strain injuries are common sporting injuries for which there are limited treatment options. Until recently, rest, eccentric exercises, biophysical procedures, drugs, such as corticosteroids, and operative treatment have been the mainstays of therapy (5). Despite the lack of authentic evidence through randomized clinical trials (RCT), the use of PRP in people has increased significantly. In recent years, the use of PRP has increased extensively in various fields, including mandibular bone grafts, sinus lifts, cosmetic surgeries, bone regeneration, and wound healing. However, rigorous evidence is lacking on the effectiveness of this method. Accordingly, the aim of this systematic review was to evaluate the efficacy and safety of the use of PRP to treat sports-related injuries.

\section{Material and methods}

\subsection{Inclusion criteria}

\subsubsection{Types of studies and interventions}

A systematic review of English-language articles was performed by searching randomized control trials in a wide range of electronic databases, including PubMed/Medline, EMBASE Wiley Online Library, Elsevier, Cochrane Database of Systematic Reviews, HTA Databases (TRIP, INAHTA), Database of Abstracts of Reviews of Effects (DARE), and NHS Economic Evaluation Database (NHS EED). For a comprehensive search, reference mining and contact with authors also were considered to cover ongoing or missed studies. The search was conducted between June 2013 and February 2014 utilizing the search terms and strategy provided below:

$(((()(((()(((($ sport$[$ tiab] OR (sport[tiab] AND medicine[tiab])) OR (sport[tiab] AND injury[tiab])) OR (sport[tiab] AND injuries[tiab])) OR (Sport[tiab] AND medecine[tiab])) OR Athlete[tiab]) OR Athletic[tiab]) OR tendon[tiab] OR tendinopathy[tiab]) OR (rotator[tiab] AND cuff[tiab])) OR (tennis[tiab] AND elbow[tiab])) OR achilles[tiab]) OR tendinitis[tiab]) OR Knee[tiab]) OR sholder[tiab]) OR shoulder[tiab]) OR ligament[tiab]) AND ((PRP [tiab] OR (platelet[tiab] AND rich[tiab])) OR (platelet[tiab] AND rich[tiab] AND plasma[tiab])).

In this study, articles with evidence levels of I and II were included (Randomized Controlled Trials and welldesigned experimental trials).

\subsubsection{Types of participants}

Because professional athletes are older than 18, we included patients of both genders who were older than 18 and had been treated with PRP for sports-related injuries or orthopedic problems.

2.1.3. Types of Intervention

Every form of Platelet rich Plasma component (e.g., injection and gel) was included, and there was not any limitation in preparing the process of PRP.

\subsubsection{Types of Comparator}

Because of the lack of relevant, matching studies, there was no limitation in comparators.

\subsubsection{Types of Outcomes}

The main outcomes were as follows: 1) Primary outcomes: Pain, activity of daily life, functions, and returning to the sports activity, 2) Secondary outcomes: Satisfaction and Quality of life: because most studies reported mean and $\mathrm{SD}$ of each group (cases/controls), quantitative analyses were done on pooling and calculating total mean differences of each group.

\subsection{Study identification and quality assessment}

One investigator (MGH) screened the titles and abstracts of the identified articles. Those that partly met the inclusion criteria were retrieved and assessed for relevance by other members of the research team (EJ and HR). Disagreements were resolved through discussion. The CASP Checklist for RCTs was used to extract the data and to assess the quality of the studies. Each article had a quality appraisal that was performed by two reviewers (MG and EJ). All discrepancies in the quality assessment were resolved through consensus.

\subsection{Analysis}

Data from eligible studies were pooled and analyzed using a fixed-effects model. Meta-analysis was conducted on the studies with the following criteria for outcomes: 1) Used same scales for same outcomes, 2) Outcomes with same follow-up times, and 3) Studies that reported mean and SD scores before and after intervention in both groups. STATA 11 software was used to conduct the statistical analysis of the data. 


\section{Results}

The search retrieved 905 articles, 12 of which met our criteria and were included in the systematic review and metaanalysis (Table 1, Figure 1).

\subsection{Assessment of Publication Bias}

Publication bias was examined by the Begg Test and Egger regression. There was no considerable publication bias (Figure 2).

Table 1. Characteristics of included studies

\begin{tabular}{|c|c|c|c|c|c|}
\hline $\begin{array}{l}\text { Ref. } \\
\text { No. }\end{array}$ & Site & Outcome measure & \begin{tabular}{|l|} 
Mean \\
follow-up
\end{tabular} & Comparator & Main results \\
\hline 18 & Achill & $\begin{array}{l}\text { Physical activity, } \\
\text { return to sport }\end{array}$ & 1 year & Saline & $\begin{array}{l}\text { No clinical and ultrasonographic superiority of platelet-rich plasma } \\
\text { injection over a placebo injection in chronic Achilles tendinopathy. }\end{array}$ \\
\hline 6 & $\begin{array}{l}\text { Lateral } \\
\text { epicondylitis }\end{array}$ & $\begin{array}{l}\text { Pain, disability and } \\
\text { function }\end{array}$ & 2 years & Corticosteroid & $\begin{array}{l}\text { The PRP group was more often successfully treated than the } \\
\text { corticosteroid. Success was defined as a reduction of } 25 \% \text { on VAS } \\
\text { or DASH scores without a reintervention after } 2 \text { years. }\end{array}$ \\
\hline 19 & Achill & $\begin{array}{l}\text { Physical activity, } \\
\text { return to desired sport }\end{array}$ & 24 weeks & Saline & $\begin{array}{l}\text { The mean VISA-A score improved significantly after } 24 \text { weeks in } \\
\text { the PRP group and in the placebo group. The increase was not } \\
\text { significantly different between both groups }\end{array}$ \\
\hline 7 & $\begin{array}{l}\text { Lateral elbow } \\
\text { epicondylitis }\end{array}$ & Pain, function & 6 months & $\begin{array}{l}\text { Autologous } \\
\text { whole blood }\end{array}$ & $\begin{array}{l}\text { The VAS score improvement was larger in group B at every follow- } \\
\text { up interval }\end{array}$ \\
\hline 8 & Patellar tendon & $\begin{array}{l}\text { Pain, physical activity, } \\
\text { satisfactory }\end{array}$ & 1 year & $\begin{array}{l}\text { Focused } \\
\text { extracorporeal } \\
\text { shock wave } \\
\text { therapy (ESWT) }\end{array}$ & $\begin{array}{l}\text { The PRP group showed significantly better improvement than the } \\
\text { ESWT group in VISA-P, VAS scores at 6- and 12-month follow-up, } \\
\text { and modified Blazina scale score at } 12 \text { month follow-up. }\end{array}$ \\
\hline 9 & Patellar tendon & $\begin{array}{l}\text { Pain, physical activity, } \\
\text { function, disability, } \\
\text { quality of life }\end{array}$ & 26 weeks & $\begin{array}{l}\text { Dry needling } \\
(\mathrm{DN})\end{array}$ & $\begin{array}{l}\text { The PRP group had improved significantly more than the DN group } \\
\text { at } 12 \text { weeks, but the difference between groups was not significant at } \\
26 \text { weeks. Lysholm scores were not significantly different between } \\
\text { groups at } 12 \text { weeks, but the DN group had improved significantly } \\
\text { more than the PRP group at } 26 \text { weeks. }\end{array}$ \\
\hline 10 & Knee & $\begin{array}{l}\text { Pain, physical function, } \\
\text { range of motion, } \\
\text { stiffness, function }\end{array}$ & 6 months & & $\begin{array}{l}\text { The PRP group recorded significantly less reduction in hemoglobin } \\
\text { and need for blood transfusion, experienced less pain and required } \\
\text { fewer narcotics than the control. There was significant difference in } \\
\text { range of motion (ROM) at three months, no significant difference in } \\
\text { wound scores and significant difference in KSS and WOMAC } \\
\text { scores at } 12 \text { weeks. However no significant difference was found at } \\
\text { six months. }\end{array}$ \\
\hline 23 & Achill & $\begin{array}{l}\text { Physical activity, } \\
\text { quality of life }\end{array}$ & 6 months & $\begin{array}{l}\text { Eccentric loading } \\
\text { program }\end{array}$ & $\begin{array}{l}\text { There was no statistically significant difference between VISA-A } \\
\text { score of groups. }\end{array}$ \\
\hline 11 & Rotator cuff & $\begin{array}{l}\text { Pain, physical activity, } \\
\text { strength in external } \\
\text { rotation, function }\end{array}$ & 2 years & & $\begin{array}{l}\text { The pain score in the treatment group was lower than the control } \\
\text { group at } 3,7,14 \text {, and } 30 \text { days after surgery. On the Simple Shoulder } \\
\text { Test (SST), University of California (UCLA), and Constant scores, } \\
\text { strength in external rotation, as measured by a dynamometer, were } \\
\text { significantly higher in the treatment group than the control group at } \\
3 \text { months after surgery (strength in external rotation [SER. There } \\
\text { was no difference between the } 2 \text { groups after } 6,12 \text {, and } 24 \text { months. } \\
\text { The follow-up MRI showed no significant difference in the healing } \\
\text { rate of the rotator cuff tear }\end{array}$ \\
\hline 12 & $\begin{array}{l}\text { Lateral } \\
\text { epicondylitis } \\
\text { and plantar } \\
\text { fasciitis }\end{array}$ & Pain, Function & 6 weeks & Corticosteroid & $\begin{array}{l}\text { In TE group no significant differences were observed relative to } \\
\text { VAS and DASH score changes between both groups. In PF patients } \\
\text { comparison of VAS and FHSQ at base line and } 6 \text { weeks after } \\
\text { treatment between control group and PRP group showed significant } \\
\text { differences for VAS, and for FHSQ. While highly significant } \\
\text { difference were observed between both groups regarding VAS and } \\
\text { FHSQ changes. }\end{array}$ \\
\hline 13 & Talus & $\begin{array}{l}\text { Pain, function, Quality } \\
\text { of life }\end{array}$ & $1-2$ years & & $\begin{array}{l}\text { The combined treatment with PRP resulted in better outcomes in } \\
\text { terms of functional scores and pain-related scores (VAS) as } \\
\text { compared to arthroscopic microfracture surgery alone. }\end{array}$ \\
\hline 14 & Rotator cuff & $\begin{array}{l}\text { Pain, physical function, } \\
\text { physical symptom }\end{array}$ & 1 year & Saline & $\begin{array}{l}\text { There was no significant difference between the groups in WORC, } \\
\text { SPADI, and VAS scores at 1-year follow-up }\end{array}$ \\
\hline
\end{tabular}




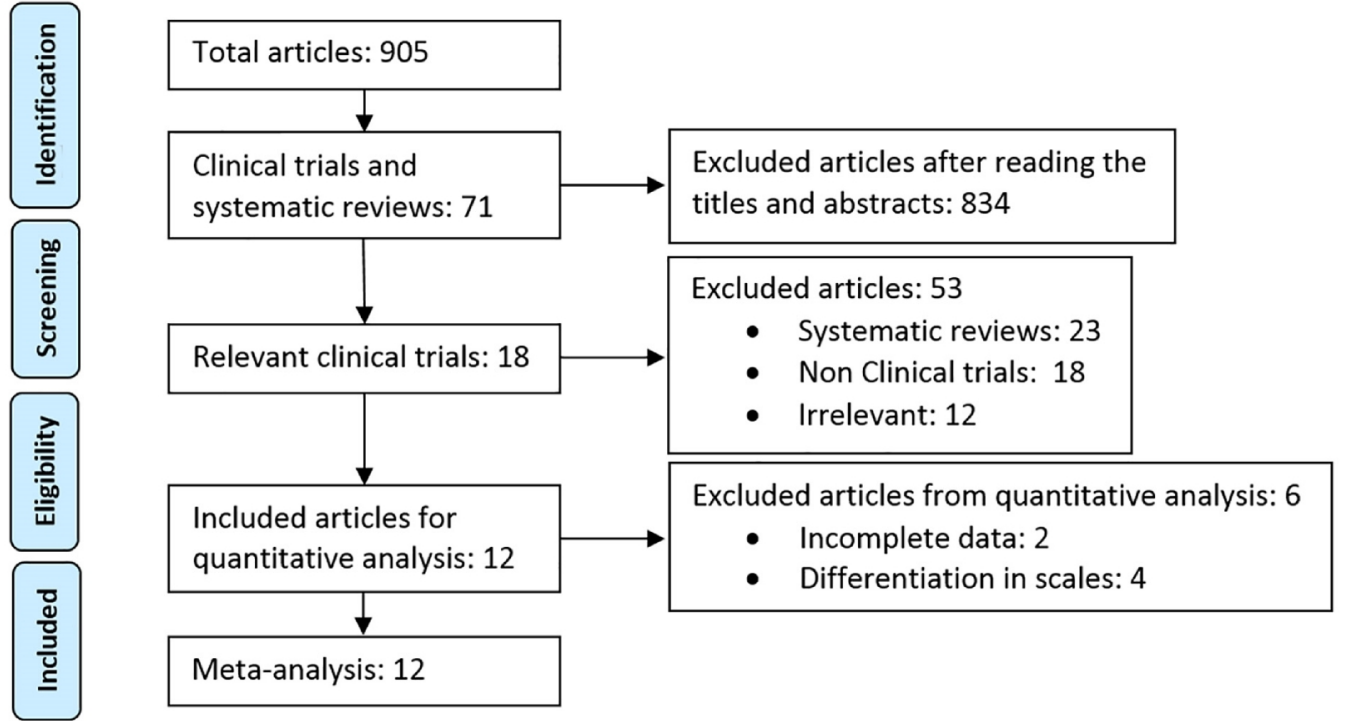

Figure 1. Article selection process

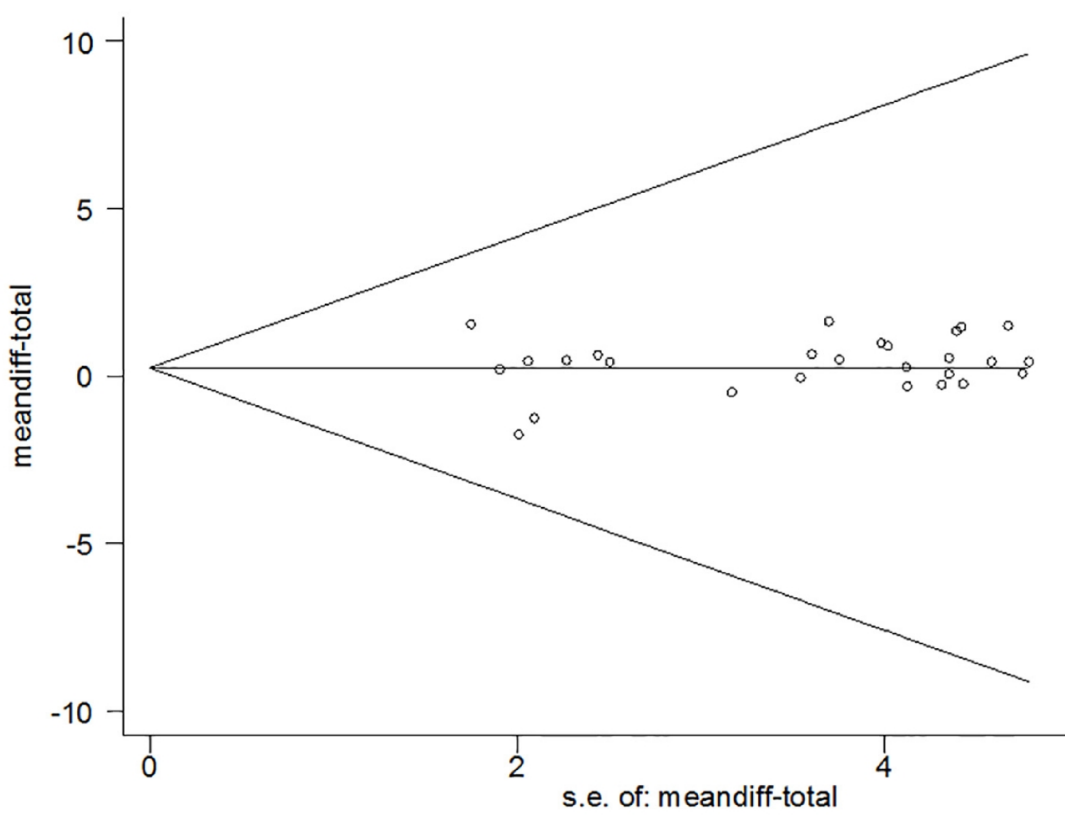

Figure 2. Funnel Plot of studies that evaluated the effect of PRP on pain reduction

\subsection{Result for primary outcomes}

There were many outcomes and scales for assessment of orthopedic issues. Our main outcomes were:

1) Pain: Several RCTs had studied the effect of PRP on pain relief using various scales for measurement of pain. We meta-analyzed 9 articles (6-14), with comparable scales, such as visual analog scale (VAS), Constant $(11,15)$, and PRTEE Pain Score $(16,17)$ to assess pain. Given the diversity in the scales and follow-up time periods, the researchers undertook the quantitative analysis only on the studies with the same scales and periodical follow-up. The most common pain assessment scale was VAS, and the followup times were then first, second, third, and sixth months and one year and two years. Meta-analysis of pain was conducted just for studies using VAS. Our meta-analysis showed no effectiveness attributable to PRP in any follow-up time period ( $\mathrm{p}=0.663$ ), (Figure 3 ).

2) Activity of daily life (physical activity): This was measured by six studies. The scales used for assessing physical activity included the Victorian Institute of Sports Assessment (VISA) (8, 18, 19), Constant (15), 
Knee Injury and Osteoarthritis Outcome Score (KOOS) (20), and PRTEE (17). Comparable data only existed in the VISA score. Quantitative analysis showed no differences between PRP treatment groups and other comparators at each follow-up time and totally $(\mathrm{p}=0.820)$.

3) Disability/Function: These outcomes were assessed by using scoring systems, such as disabilities of the arm, shoulder, and hand (DASH) $(6,12)$, International Knee Documentation Committee (IKDC) (20-22), Liverpool elbow score, Patient-rated Tennis Elbow Evaluation-PRTEE (16), and foot health status questionnaire-FHSQ (12). There was no consistency in the final results.

4) Return to sports: Return to sports was addressed in some studies $(18,19)$. There was no consistency in the scales and follow-up times on this outcome. Therefore, no quantitative analysis was possible.

\subsection{Result for secondary outcomes}

Quality of life: This was assessed in three studies $(9,13,23)$, and the results indicated that PRP was not superior to the other comparators. To assess the patients' satisfaction, the researchers various tools, such as SF-12 and EQ5D.Satisfaction: There was no consistency in the assessment methods of satisfaction, and there was no significant difference in this secondary outcome measure $(8,19)$.

\subsection{Part of body}

PRP was used in many tendons, such as Achilles, knee, elbow, patellar, and talus, but there was no similarity in the clinical improvements. In three RCTs, within which PRP was used on the Achilles tendon $(18,19,23)$, the overall result was unsatisfactory. Filardo et al. (20), Valentí Nin et al. (22), and Aggarwal (10) evaluated the effect of PRP on the knee. However, the results were just in favor of PRP in Aggarwal et al.'s study. From five studies of the elbow $(6,7,12,16,17)$, only two studies (Gosens and Thanasas et al.) confirmed PRP. Moreover, five studies of the Patellar Tendon and Talus $(8,12,13,21,24)$ showed some benefit for PRP, with the exception of Omar et al. (12). Castricini et al. (15), Randelli et al. (11), and Kesikburun et al. (14) studied the effects of PRP on Rotator Cuff with Randelli's study in favor of PRP.

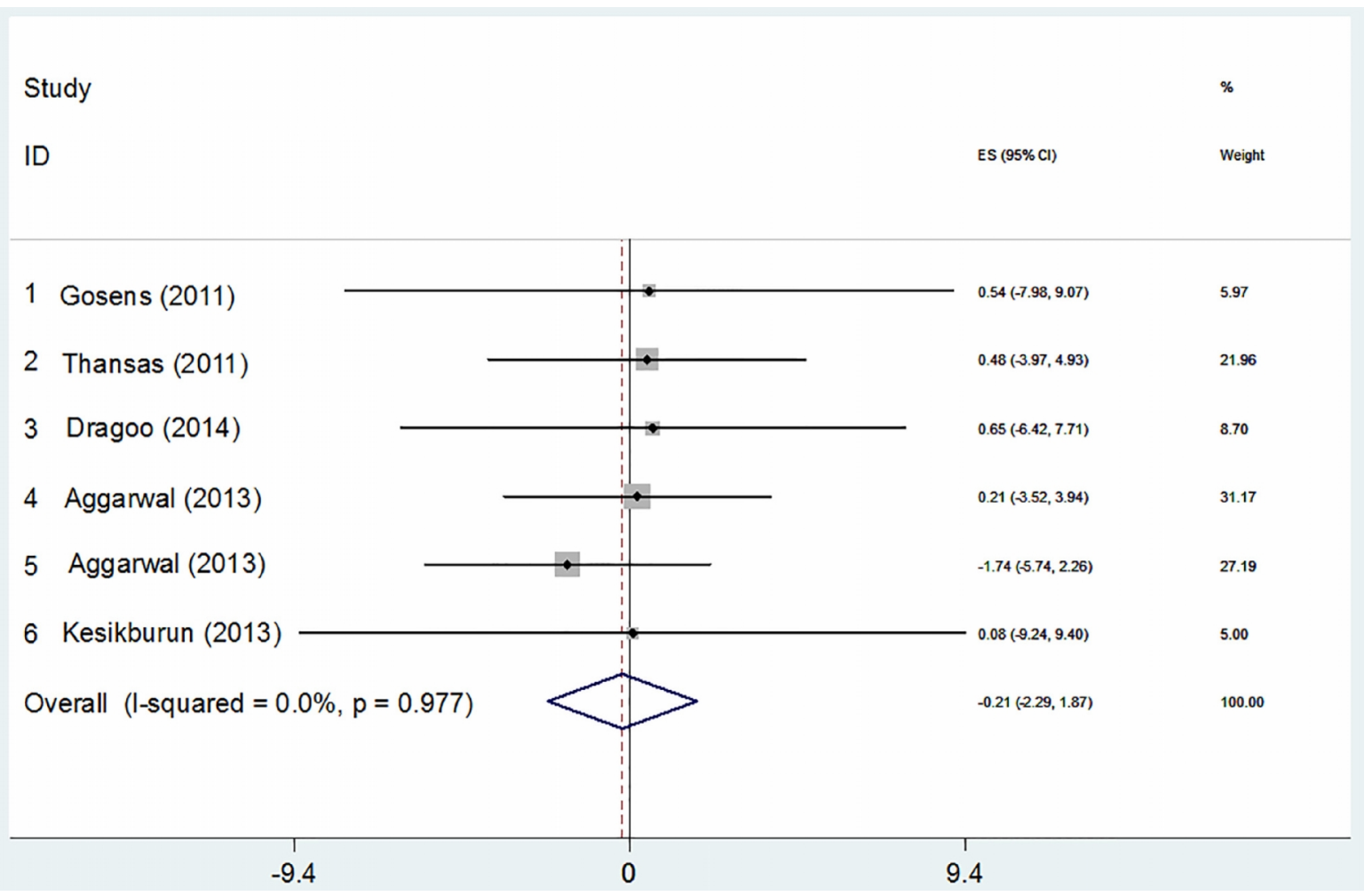

Figure 3. Forest plot of pain scores (VAS) in the PRP treatment group compared to the control group at the threemonth follow-up

\section{Discussion}

Our systematic review and meta-analysis results showed inconclusive evidence concerning the clinical benefit of using PRP for orthopedics and sports-related injuries. Of 18 RCTs, 11 did not show any clinical benefit for PRP, and 
the rest was not strong enough in terms of population and effect size to support the efficacy of PRP in pain reduction $(p=0.663)$ or function improvement $(p=0.820)$. Although this systematic review and meta-analysis showed that PRP was as effective as other comparators in pain reduction, its results were inconsistent with Malavolta et al. (25) and Hamid et al. (26), but, still, there are studies that have shown more benefit in pain relief, such as Gosens et al. (6) and de Almeida et al. (21). Despite these well designed RCT's, a large number of the studies that claimed more benefits on pain reduction of PRP generally were not RCT $(27,28)$.In some studies, PRP was used along with an orthopedic operation, within them anatomical improvements were also expected besides other outcomes (e.g., pain relief). For example, Castricini et al. (15) and Valentí Nin et al. (22) reported no effect from PRP on Arthroscopic Rotator Cuff Repair and Anterior Cruciate Ligament Allograft Healing. Nonetheless, de Almeida et al. (21), Aggarwal et al. (10) and Randelli et al. (11), who used PRP during surgery, reported some benefits, such as repair, less pain, and less bleeding after surgery. As mentioned earlier, PRP had no effect on the time to return to sports. The main problem in assessment of this outcome was finding similar and measurable scales to compare the studies. Overall, the results on PRP effectiveness in muscle and skeleton problems were largely inconsistent. Improvement or otherwise by PRP can be discussed from various perspectives:

1) Individual characteristics: Characteristics and severity of sports-related injuries may vary at different ages. Insufficient studies exist that have evaluated the effect for different age ranges and genders along with that of PRP. Hamid et al. studied those with mean age of 21 whose return to sports was better in the PRP group than in the controls (26). Mean age of PRP group in de Almeida (21) and Vetrano (8) studies was around 26; their results were in favor of PRP, too. Despite these positive results in young people, in Valentí Nin's (22) study on participants with a mean age of 26, the results did not exhibit any benefits for PRP. It could be argued that the age and gender have some effect on PRP. For instance, studying 637 people, Marques et al. found that platelet count in women and young people were higher than in men and older people (29).

2) Follow up time: Different follow-up time periods after PRP treatment were found for sports-related and orthopedic injuries in the studies, i.e., from a few days (28) to two years (6) and even four years (9). The results were sometimes different on each follow up time. For example, in Dragoo et al.'s study, VISA score confirmed PRP effect on week 12, but did not on week 26 (9). The longest follow up time was seen in Filardo et al.'s study. They followed up patients for four years and found affirmative results for PRP (30).

3) Duration of injuries: Duration of tendon injuries may have an effect on the improvement and effectiveness of PRP. Acute or chronic injuries probably respond differently to treatment procedures. Kesikburun et al. (14) and Zumstein et al. (31), who worked on Chronic Rotator Cuff Tendinopathy and tears, found no more benefits for PRP. deJonge et al. (18) and de Vos et al. (19) both studied the effect of PRP on Chronic Achilles Tendinopathy, and they obtained the same results. However, in Thanasas et al.'s study in which PRP was used for chronic lateral elbow epicondylitis, it had a positive effect just on pain reduction in the short term, and, in terms of Liverpool elbow score, there was no significant difference between the groups.

4) Concerning the differentiation on PRP preparation and applications, now some new aspects are emerging; Bausset et al. (32) showed that using local anesthesia to prevent pain during PRP injection could compromise the therapeutic effect of PRP. Even Aoto et al. (33) examined circadian variation of growth factor levels in PRP, but they found no significant differences in platelet rate and white blood cell in the PRP samples throughout the course of the day.

Regarding the study limitations, there were different protocols to prepare and use the PRP (single or double-spinning approach); various forms of PRP (gel, injection or scaffold), final volume of PRP (2-8 ml), kits used, time and number of centrifuge, PRP with/without coagulant and activators, Platelet count, PRP multiple application (2-4). Some studies did not have any description about PRP preparation system. According to these limitations, judgment on the effectiveness of PRP across the published studies might be made prudently.

\section{Conclusions}

Although this study could not argue in favor of PRP application for physical activity improvement and pain reduction, there are some studies that showed some sort of benefits for PRP. These results show that, until strong evidence can be produced, there should be some limitations on the current applications of PRP. Further welldesigned RCTs are needed with large populations to investigate the real effects of PRP on sports-related injuries. It is necessary to define a standard protocol for PRP preparation and application.

\section{Acknowledgments:}

This study was extracted from the first author's postgraduate thesis, and it was funded by the National Institute of Health Research (No. 241/91372). 


\section{Conflict of Interest:}

There is no conflict of interest to be declared.

\section{Authors' contributions:}

All authors contributed to this project and article equally. All authors read and approved the final manuscript.

\section{References:}

1) Arnoczky SP, Delos D, Rodeo SA. What Is Platelet-Rich Plasma? Oper Tech Sports Med. 2011; 19(3): 142-8. doi: 10.1053/j.otsm.2010.12.001.

2) Marx RE. Platelet-rich plasma (PRP): what is PRP and what is not PRP? Implant Dent. 2001; 10(4): 225-8. doi: 10.1097/00008505-200110000-00002, PMID: 11813662.

3) Creaney L, Hamilton B. Growth factor delivery methods in the management of sports injuries: the state of play. Br J Sports Med. 2008; 42(5): 314-20. doi: 10.1136/bjsm.2007.040071, PMID: 17984193.

4) Taylor D, Petrera M, Hendry M, Theodoropoulos JS. A Systematic Review of the Use of Platelet-Rich Plasma in Sports Medicine as a New Treatment for Tendon and Ligament Injuries. Clin J Sport Med. 2011; 21(4): 344-52. doi: 10.1097/JSM.0b013e31821d0f65, PMID: 21562414.

5) Ackermann Pw-Renstrom P. Tendinopathy in sport. Sports Health. 2012; 4(3): 193-201, PMID: 23016086.

6) Gosens T, Peerbooms JC, van Laar W, den Oudsten BL. Ongoing Positive Effect of Platelet-Rich Plasma Versus Corticosteroid Injection in Lateral Epicondylitis; a Double-Blind Randomized Controlled Trial With 2-year Follow-up. Am J Sports Med. 2011; 39(6): 1200-8. doi: 10.1177/0363546510397173, PMID: 21422467.

7) Thanasas C, Papadimitriou G, Charalambidis C, Paraskevopoulos I, Papanikolaou A. Platelet-rich plasma versus autologous whole blood for the treatment of chronic lateral elbow epicondylitis: a randomized controlled clinical trial. Am J Sports Med. 2011; 39(10): 2130-4. doi: 10.1177/0363546511417113, PMID: 21813443.

8) Vetrano M, Castorina A, Vulpiani MC, Baldini R, Pavan A, Ferretti A. Platelet-rich plasma versus focused shock waves in the treatment of jumper's knee in athletes. Am J Sports Med. 2013; 41(4): 795-803. doi: 10.1177/0363546513475345, PMID: 23408591.

9) Dragoo JL, Wasterlain AS, Braun HJ, Nead KT. Platelet-Rich Plasma as a Treatment for Patellar Tendinopathy A Double-Blind, Randomized Controlled Trial. Am J Sports Med. 2014; 42(3): 610-8. doi: 10.1177/0363546513518416, PMID: 24481828.

10) Aggarwal AK, Shashikanth V, Marwaha N. Platelet-rich plasma prevents blood loss and pain and enhances early functional outcome after total knee arthroplasty: a prospective randomised controlled study. Int Orthop 2014; 38(2): 387-95. doi: 10.1007/s00264-013-2136-6, PMID: 24114251.

11) Randelli P, Arrigoni P, Ragone V, Aliprandi A, Cabitza P. Platelet rich plasma in arthroscopic rotator cuff repair: a prospective RCT study, 2-year follow-up. J Shoulder Elbow Surg. 2011; 20(4): 518-28. doi: 10.1016/j.jse.2011.02.008, PMID: 21570659.

12) Omar AS, Ibrahim ME, Ahmed AS, Said M. Local injection of autologous platelet rich plasma and corticosteroid in treatment of lateral epicondylitis and plantar fasciitis: Randomized clinical trial. Egypt Rheumatol. 2012; 34(2): 43-9. doi: 10.1016/j.ejr.2011.12.001.

13) Guney A, Akar M, Karaman I, Oner M, Guney B. Clinical outcomes of platelet rich plasma (PRP) as an adjunct to microfracture surgery in osteochondral lesions of the talus. Knee Surg Sports Traumatol Arthrosc. 2015; 23(8): 2384-9. doi: 10.1007/s00167-013-2784-5, PMID: 24292979.

14) Kesikburun S, Tan AK, Yılmaz B, Yaşar E, Yazıcıoğlu K. Platelet-Rich Plasma Injections in the Treatment of Chronic Rotator Cuff Tendinopathy A Randomized Controlled Trial With 1-Year Follow-up. Am J Sports Med. 2013; 41(11): 2609-16. doi: 10.1177/0363546513496542, PMID: 23893418.

15) Castricini R, Longo UG, De Benedetto M, Panfoli N, Pirani P, Zini R, et al. Platelet-Rich Plasma Augmentation for Arthroscopic Rotator Cuff Repair A Randomized Controlled Trial. Am J Sports Med. 2011; 39(2): 258-65. doi: 10.1177/0363546510390780, PMID: 21160018.

16) Krogh TP, Fredberg U, Stengaard-Pedersen K, Christensen R, Jensen P, Ellingsen T. Treatment of Lateral Epicondylitis With Platelet-Rich Plasma, Glucocorticoid, or Saline A Randomized, Double-Blind, PlaceboControlled Trial. Am J Sports Med. 2013; 41(3): 625-35. doi: 10.1177/0363546512472975, PMID: 23328738

17) Creaney L, Wallace A, Curtis M, David C. Growth factor-based therapies provide additional benefit beyond physical therapy in resistant elbow tendinopathy: a prospective, single-blind, randomised trial of 
autologous blood injections versus platelet-rich plasma injections. Br J Sports Med. 2011; 45(12): 966-71. doi: $10.1136 /$ bjsm.2010.082503.

18) de Jonge S, de Vos RJ, Weir A, van Schie HT, Bierma-Zeinstra SM, Verhaar JA, et al. One-Year Followup of Platelet-Rich Plasma Treatment in Chronic Achilles Tendinopathy A Double-Blind Randomized Placebo-Controlled Trial. Am J Sports Med. 2011; 39(8): 1623-9. doi: 10.1177/0363546511404877, PMID: 21602565.

19) de Vos RJ, Weir A, van Schie HT, Bierma-Zeinstra SM, Verhaar JA, Weinans H, et al. Platelet-rich plasma injection for chronic Achilles tendinopathy: a randomized controlled trial. JAMA. 2010; 303(2): 144-9. doi: 10.1001/jama.2009.1986, PMID: 20068208.

20) Filardo G, Kon E, Di Martino A, Di Matteo B, Merli M, Cenacchi A, et al. Platelet-rich plasma vs hyaluronic acid to treat knee degenerative pathology: study design and preliminary results of a randomized controlled trial. BMC Musculoskelet Disord. 2012; 13(1): 229. doi: 10.1186/1471-2474-13-229, PMID: 23176112, PMCID: PMC3532098.

21) de Almeida AM, Demange MK, Sobrado MF, Rodrigues MB, Pedrinelli A, Hernandez AJ. Patellar Tendon Healing With Platelet-Rich Plasma A Prospective Randomized Controlled Trial. Am J Sports Med. 2012; 40(6): 1282-8. doi: 10.1177/0363546512441344, PMID: 22472272.

22) Nin JR, Gasque GM, Azcárate AV, Beola JD, Gonzalez MH. Has Platelet-Rich Plasma Any Role in Anterior Cruciate Ligament Allograft Healing? Arthroscopy. 2009; 25(11): 1206-13. doi: 10.1016/j.arthro.2009.06.002, PMID: 19896041.

23) Kearney R, Parsons N, Costa M. Achilles tendinopathy management A pilot randomised controlled trial comparing platelet-rich plasma injection with an eccentric loading programme. Bone Jt Res. 2013; 2(10): 227-32. doi: 10.1302/2046-3758.210.2000200.

24) Castillo TN, Pouliot MA, Kim HJ, Dragoo JL. Comparison of growth factor and platelet concentration from commercial platelet-rich plasma separation systems. Am J Sports Med. 2011; 39(2): 266-71. doi: 10.1177/0363546510387517, PMID: 21051428.

25) Malavolta EA, Gracitelli MEC, Neto AAF, Assunção JH, Bordalo-Rodrigues M, de Camargo OP. PlateletRich Plasma in Rotator Cuff Repair A Prospective Randomized Study. Am J Sports Med. 2014: 42(10): 2446-54. doi: 10.1177/0363546514541777, PMID: 25086065.

26) A Hamid MS, Mohamed Ali MR, Yusof A, George J, Lee LPC. Platelet-Rich Plasma Injections for the Treatment of Hamstring Injuries A Randomized Controlled Trial. Am J Sports Med. 2014: 42(10): $2410-8$. doi: 10.1177/0363546514541540, PMID: 25073598.

27) Guler O, Mutlu S, Isyar M, Seker A, Kayaalp M, Mahirogullari M. Comparison of short-term results of intraarticular platelet-rich plasma (PRP) and hyaluronic acid treatments in early-stage gonarthrosis patients. Eur J Orthop Surg Traumatol. 2015; 25(3):509-13. doi: 10.1007/s00590-014-1517-x, PMID: 25085316.

28) Bubnov R, Yevseenko V, Semeniv I. Ultrasound guided injections of Platelets Rich Plasma for muscle injury in professional athletes. Comparative study. Foot and ankle. 2013; 15(2): 101-5. doi: 10.11152/mu.2013.2066.152.rb1vy2, PMID: 23702498.

29) Marques FP, Ingham SJM, Forgas A, FrancioziCEdS, Sasaki PH, Abdalla RJ. A manual method to obtain platelet rich plasma. Acta Ortop Bras. 2014; 22(2): 75-7. doi: 10.1590/1413-78522014220200798, PMCID: PMC4031249.

30) Filardo G, Kon E, Di Matteo B, Di Martino A, Tesei G, Pelotti P, et al. Platelet-rich plasma injections for the treatment of refractory Achilles tendinopathy: results at 4 years. Blood Transfus. 2014: 12(4): 533-40. doi: 10.2450/2014.0289-13, PMID: 24960641.

31) Zumstein MA, Rumian A, Lesbats V, Schaer M, Boileau P. Increased vascularization during early healing after biologic augmentation in repair of chronic rotator cuff tears using autologous leukocyte-and plateletrich fibrin (L-PRF): a prospective randomized controlled pilot trial. J Shoulder Elbow Surg. 2014; 23(1): 3 12. doi: 10.1016/j.jse.2013.08.017, PMID: 24331121.

32) Bausset O, Magalon J, Giraudo L, Loui M-L, Serratrice N, Frere C, et al. Impact of local anaesthetics and needle calibres used for painless PRP injections on platelet functionality. Muscles Ligaments Tendons J. 2014; 4(1): 18-23. PMID: 24932442, PMCID: PMC4049644.

33) Aoto K, Kanamori A, Yoshioka T, Uemura K, Sakane M, Yamazaki M. Circadian Variation of Growth Factor Levels in Platelet-Rich Plasma. Clin J Sport Med. 2014; 4(1): 18-23. doi: 10.1097/JSM.0000000000000080, PMID: 24932442, PMCID: PMC4049644. 